\title{
Comunicação química, feromonas e controle de insectos ${ }^{1}$

\author{
José A.S. Cavaleiro, Augusto C. Tomé ${ }^{a}$
}

Pretende-se dar, com este trabalho, uma contribuição para que a relevância da Química, na compreensão dos problemas da Ecologia, possa ser evidenciada. Os compostos envolvidos constituem uma gama estruturalmente muito vasta, havendo alguns muito simples $e$ outros com estruturas mais complexas. Os assuntos de Ecologia Quimica podem, assim, ser introduzidos, com niveis diferentes de desenvolvimento, em cursos gerais e em cursos avançados de Química Orgânica.

\section{INTRODUÇÃO}

A fome a nível mundial é, sem dúvida, um dos maiores problemas da actualidade. A população mundial actual é cerca de 4500 milhões de habitantes e os demógrafos 2 estimam que no ano 2000 seja de 6000 -7000 milhões e que atinja o valor de $10000-16000$ milhões no ano 2100; poder-se-á, assim, prever que a fome aumente a breve prazo, a não ser que o rendimento das culturas, a nível mundial, aumente consideravelmente e sem que isso se traduza por encargos económicos elevados, o que não tem, infelizmente, acontecido.

A existência de pragas (ou pestes), destruindo grande parte das provisões alimentares, tem tido também um significado muito especial no agravamento da situação de fome. Para contrariar este facto o Homem tem recorrido sistematicamente ao uso de compostos de acção biocida, quase todos de origem sintética, os quais são vulgarmente designados por pesticidas. E assim atingiu-se uma situação em que não é possível produzir e armazenar a quase totalidade dos produtos agrícolas sem utilizar grandes quantidades desses produtos químicos. Actualmente são aplicadas em todo o mundo cerca de 2 milhões de toneladas ou seja cerca de $0,5 \mathrm{~kg}$ por pessoa 2 . A situação actual, em Portugal 3 , relativa ao ataque, com produtos fitofarmacêuticos, a algumas pragas de insectos existentes em certas culturas e sementes armazenadas é exposta na Tabela 1 .

O uso intensivo de pesticidas, que poderá ser designado por "Luta Química", não tem resolvido, de modo aceitável, o problema. De facto, para se alcançarem resultados satisfatórios de protecção, são necessários tratamentos cada vez mais frequentes e em doses cada vez mais elevadas. Assim os custos têm aumentado progressivamente e, talvez ainda pior, os problemas de poluição do meio ambiente atingem níveis alarmantes, ameaçando até a destruição do equilíbrio ecológico.

Uma vez que a "Luta Química" sozinha não satisfaz, nem no plano técnico, nem no económico, nem no ambiental, começou recentemente a ser desenvolvida uma nova técnica de luta contra as pragas de acções e meios complementares adequados, a qual é designada por "Protecção Integrada". Esta, traduzindo na prática a reunião de dois conceitos ("Luta Química" e
“Luta Biológica”), foi definida, em 1973, pela Organização Internacional de Luta Biológica 5, como sendo "um processo de luta contra os organismos nocivos, que utilize um conjunto de métodos que satisfaçam as exigências económicas, ecológicas e toxicológicas e que dê carácter prioritário às aç̧̃es que fomentem a limitação natural dos inimigos das culturas, tendo em consideração os níveis económicos de ataque".

A estratégia da "Protecção Integrada" será assim limitativa ou correctiva; a sua "arma" mais recente, e certamente a que mais vantagens oferece, é designada por "Comunicação Química”.

\section{A COMUNICAÇÃO QUíMICA NA NATUREZA}

A ideia de que os insectos (e até plantas!) comunicam entre si, já não é nova. De facto já no final do séc. XVII Ray 6 sugeriu que o odor das traças fêmeas atraía os machos da mesma espécie. Em 1779, Bonnett 6 notou que algumas espécies de formigas usavam percursos feitos por fêmeas para incentivarem os machos da mesma espécie a transportarem a comida e, em 1879, Fabre ${ }^{6}$ referiu que a atracção entre borboletas se baseia em odor. Plinio, na época do Império Romano, reconheceu que a nogueira envenena as outras plantas cobertas pela sua copa ? . Porém, só recentemente (em 1959) com o isolamento do primeiro composto químico envolvido nessas funções, foi possível concluir que aquela comunicação é efectuada através da segregação de compostos químicos, sendo por isso designada por “Comunicação Química”.

\section{TIPOS DE COMPOSTOS ENVOLVIDOS NA COMUNICAÇÃO QUÍMICA}

Os compostos químicos que "transportam" as mensagens trocadas entre membros da mesma ou de diferentes espécies são designados genericamente por "Semioquímicos" (termo derivado do grego "Semeion" que significa marca ou sinal). Estes compostos, sob um ponto de vista funcional, podem ser divididos nos grupos seguintes 6:

a) os usados na comunicação entre seres de espécies diferentes, designando-se por alomonas os que beneficiam o emissor e por cairomonas os que beneficiam o receptor;

b) os usados na comunicação entre seres da mesma espécie que se designam por feromonas.

\footnotetext{
a Departamento de Quimica, Universidade de Aveiro, 3800 Aveiro.
} 


\begin{tabular}{|c|c|c|c|c|c|c|c|c|c|c|c|c|c|c|c|c|c|c|c|c|c|c|c|c|}
\hline & \multicolumn{9}{|c|}{ Lepidópteros } & \multicolumn{5}{|c|}{ Hemipteros } & \multirow{2}{*}{ 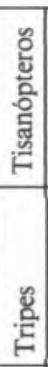 } & \multirow{2}{*}{ 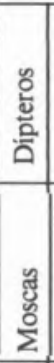 } & \multicolumn{2}{|c|}{ 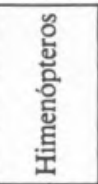 } & \multicolumn{6}{|c|}{ Coleópteros } \\
\hline & $\begin{array}{l}\text { đี } \\
\text { త్ర } \\
\text { Z }\end{array}$ & 壱 & 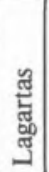 & ஜֶ & 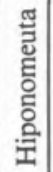 & $\begin{array}{l}\text { 䔍 } \\
\text { 㥕 } \\
\text { 点 }\end{array}$ & \begin{tabular}{l}
$\mathbb{J}$ \\
\multirow{J}{J}{} \\
$\mathbb{N}$
\end{tabular} & $\begin{array}{l}\text { 을 } \\
\text { 总 } \\
\text { in }\end{array}$ & 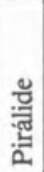 & $\frac{8}{8}$ & 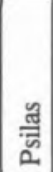 & 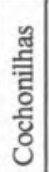 & 总 & שั. & & & 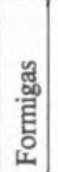 & 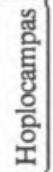 & 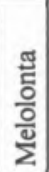 & 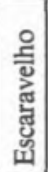 & 㞧 & 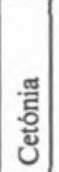 & $\begin{array}{l}\text { 을 } \\
\text { 흔 } \\
\text { 인 }\end{array}$ & 㬅 \\
\hline Arroz & & & $x$ & $\times$ & & & & & & $x$ & & & & & & & & & & & & & & \\
\hline Milho & $\times$ & $x$ & & $\times$ & & & & & & & & & & & & & & & $x$ & & & & & $x$ \\
\hline Trigo & & & & & & & & & & $x$ & & & & & & & & & & & & $x$ & & \\
\hline Batateiras & $\times$ & & & $\times$ & & & & & & $x$ & & & & & & & & & $\times$ & $x$ & & & & $x$ \\
\hline Cebolas & $\times$ & & $\times$ & & & & & & & $x$ & & & & & & $\times$ & & & & & & & & \\
\hline Cenouras & & & $x$ & $\times$ & & & & & & $x$ & & & & & & $x$ & & & & & & & & \\
\hline Couves & $\times$ & & $x$ & & & & & & & $\times$ & & & & $\times$ & & $\times$ & & & & & $x$ & & $x$ & $x$ \\
\hline Tomateiros & $\times$ & & $x$ & $x$ & & & & & & $\times$ & & & & $x$ & $x$ & $\times$ & & & $\times$ & & & & & $x$ \\
\hline Ameixieiras e Cerejeiras & & & $x$ & & & & & $\times$ & & $\times$ & & $\times$ & & & & $\times$ & & & & & & & & \\
\hline Macieiras & $\times$ & & $x$ & & & $x$ & & $\times$ & & $\times$ & $\times$ & $\times$ & $x$ & & $x$ & & & & & & & & & \\
\hline Pereiras & $\times$ & & $x$ & & $x$ & $x$ & $\times$ & & $\times$ & $\times$ & $\times$ & $\times$ & & $\times$ & $x$ & & $x$ & & & & $x$ & & & \\
\hline Pessegueiros & & $x$ & $x$ & & & & $\times$ & & & & & & & & $\times$ & $\times$ & $\times$ & $x$ & & & & & & \\
\hline Morangueiros & $\times$ & & $x$ & & & & & & & $\times$ & & & & & & & & & & & & & & \\
\hline Citrinos & & & & & & & & & & $\times$ & & $\times$ & & & & $\times$ & & & & & & & $x$ & \\
\hline Meloeiros & $\times$ & & $x$ & & & & & & & $\times$ & & & & & $x$ & & & & & & & & $x$ & \\
\hline Videiras & $\times$ & $\times$ & & & & & & & $\times$ & & & $\times$ & & & & & $x$ & & & & $x$ & & $x$ & \\
\hline Oliveiras & & $x$ & & & & & & & & & & $\times$ & & & $x$ & $\times$ & & & & & & & $x$ & \\
\hline Sementes armazenadas * & $\times$ & & & & & & & & & $\times$ & & & & & & $x$ & & & & & $x$ & & & $x$ \\
\hline
\end{tabular}

Tabela 1

Algumas pragas de insectos de certas culturas e de sementes armazenadas, que são combatidas, em Portugal, com produtos fitofarmacêuticos 3 * Estão identificadas 155 espécies de insectos prejudiciais aos produtos armazenados em Portugal 4

\section{Alomonas}

Frequentemente, mas nem sempre, as alomonas são usadas para defesa 7. Têm sido isoladas de diversas fontes, desde micro-organismos a plantas e animais superiores. Assim, por exemplo, muitos artrópodes usam "defesas químicas", que são alomonas, para deter os seus predadores, as quais são constituídas por diversas quinonas, aldeídos, cetonas e ácidos carboxílicos alifáticos. Também certas plantas usam uma grande variedade de alomonas para se protegerem de insectos fitófagos e de outros herbívoros. Algumas dessas alomonas têm propriedades tóxicas. O Homem tira partido desse facto ao usar produtos de origem vegetal, por exemplo, como insecticidas; estão, neste caso, a nicotina (1), a rotenona (2) e a piretrina-I (3). As plantas

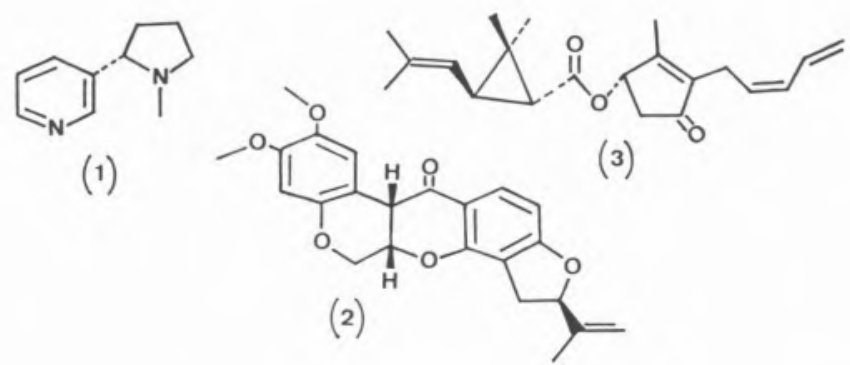

contêm ainda outras alomonas que, não sendo necessariamente compostos tóxicos, têm propriedades enfastiantes, evitando assim serem comidas por insectos e outros animais. Porém, nem todas as alomonas são usadas com objectivos de defesa. Elas estão também envolvidas na atracção de insectos (abelhas, por exemplo) para a polinização.

\section{Cairomonas}

As Cairomonas são mensageiros químicos que favorecem os organimos receptores. Servem, dum modo geral, para ajudar os predadores a encontrarem as suas presas (os emissores) ou, nalguns casos, para ajudar as presas a escaparem-se dos seus predadores (que serão agora os emissores). ${ }^{7}$

Apesar de haver um número menor de trabalhos sobre este grupo de compostos do que sobre o das alomonas, poder-se-ão, contudo, referir, entre outros, os exemplos indicados a seguir.

Algumas plantas da família das Cucurbitáceas produzem um grupo de compostos tóxicos, de sabor amargo, para se protegerem de ataques de herbívoros; um desses compostos é a cucurbitacina B (4). Esta funciona como cairomona para certas espécies de coleópteros seleccionarem as suas fontes de alimentação. 


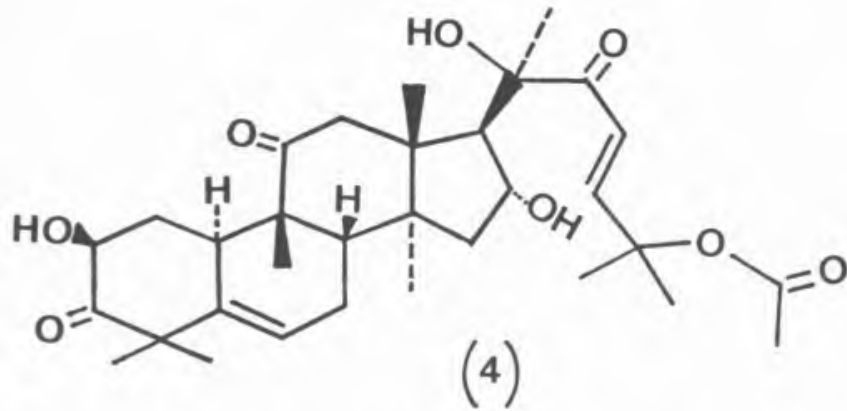

Certos moluscos marinhos detectam o cheiro das suas predadoras (estrelas do mar) e isso basta-lhes para se escaparem. Também o salmão do género "Oncorhynchus" suspende a sua migração ao aperceber-se da presença de L-serina, um amino-ácido presente na pele de mamíferos seus predadores (Homem, urso, foca).

\section{Feromonas}

A designação de feromonas foi criada em 1959 por Karlson e Luscher, recorrendo às raizes etimológicas gregas (pherein = transferir, transportar e horman =estimular, excitar) 7 .

As feromonas constituem um grupo de mensageiros químicos, voláteis ou solúveis em água, os quais, uma vez lançados no Ambiente, em quantidades mínimas, influenciam o comportamento de indivíduos da mesma espécie do produtor.

O grupo das feromonas é o que tem despertado maior interesse. É hoje sabido que a produção de feronomas tem lugar em glândulas exócrinas. A sua emissão é descontínua, por esguichos e com variação em quantidade. A quase totalidade dos estudos sobre estes compostos tem sido feita com insectos e, em consequência, são animadoras as perspectivas do seu uso no controle desses mesmos insectos.

Convém notar que apesar dos compostos semioquímicos estarem divididos em três grupos, estes não são mutuamente exclusivos. O cheiro das flores, usado para atrair os insectos necessários à polinização, é provocado por compostos que, para as flores, são considerados alomonas mas para os insectos são cairomonas, pois permitem-lhes detectar fontes de néctar. De igual modo, as feromonas duma espécie podem também actuar como cairomonas se estas servirem para os predadores dessa espécie detectarem as suas presas.

\section{A DESCOBERTA DAS FEROMONAS}

Apesar da curiosidade ser uma característica humana muito antiga, só em 1959 é que, após anos de intenso trabalho e o sacrifício de milhões de fêmeas do bicho-da-seda, Bombyx mori, se conseguiu isolar a primeira feromona 8. Mais tarde, com a sua síntese, ficou definitivamente provado tratar-se, de facto, da feromona sexual que é segregada pelo bicho-da-seda fêmea para atrair o macho. Esta feromona, que foi designada por "Bombicol", é o (10E,12Z)-10,12-hexadecadienol (5).

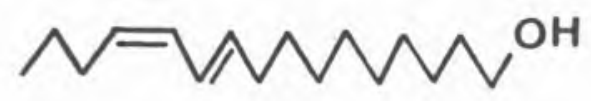

O "Bombicol" foi inicialmente considerado como sendo componente único da feromona. No entanto, recentemente, descobriu-se que a glândula abdominal da fêmea virgem contém, além do "Bombicol", o correspondente aldeído, (E,Z)-10,12-hexadecadienal ou "Bombical", não estando ainda elucidado o seu significado biológico.

É natural que se pergunte porque é que se levaram tantos anos para se isolar e caracterizar a primeira feromona. A resposta está no facto da quantidade de feromona encontrada na glândula do insecto ser aproximadamente de $1 \mathrm{ng}$ e ser necessário equipamento altamente sensivel para a localizar, extrair e analisar. $\mathrm{O}$ aparecimento de aparelhos altamente sofisticados, em particular de cromatografia de gás - espectrometria de massa e de ressonância magnética nuclear impulsionou grandemente a descoberta de novas feromonas.

Muitos estudos têm sido feitos nos últimos 20 anos, visando a elucidação estrutural das feromonas sexuais de traças, devido ao grande impacto desses lepidópteros como pragas. Assim, em 1965 já eram conhecidas 3 dessas feromonas, em 1970 conheciam-se 20 e em 1975 eram conhecidas 40 . O número dessas feromonas aumentou para 100 em 1978 e para várias centenas no início de 1984. Estes excelentes trabalhos de elucidação estrutural têm sido acompanhados pelo estabelecimento de métodos de síntese para esses compostos e por estudos fascinantes de relação estrutura-actividade.

\section{TIPOS DE FEROMONAS}

Existem vários tipos de feromonas, sendo estas classificadas de acordo com o estímulo que provocam no seu receptor. Assim, há feromonas que provocam efeitos fisiológicos por períodos mais ou menos longos (como, por exemplo, as que indicam a "casta" de certas familias de insectos) e as que têm uma acção instantânea e reversível (como por exemplo, as feromonas de alarme, de agregação, de percurso e sexuais) 7 .

O exemplo já clássico ${ }^{9}$ duma feromona de efeito fisiológico prolongado é o ácido (E)-9-oxo-2-decenoico produzido pelas rainhas das abelhas Apis mellifera. Quando a rainha morre as outras abelhas detectam a sua falta pela ausência desse ácido na colmeia. Nesse caso as obreiras alimentam as novas larvas em desenvolvimento e destas surgirá uma nova rainha. Aquele ácido é ainda responsável pela inibição do desenvolvimento dos ovários das obreiras, tornando-as estéreis.

Como já foi referido, são diversas as feromonas de acção imediata e reversível. As de alarme originam mecanismos de defesa, como os de voo e de queda, em indivíduos da mesma colónia (de afídeos, por exemplo) quando são atacados.

As feromonas de agregação originam a formação de enxames num determinado lugar considerado próprio para a colonização pelos primeiros indivíduos que aí chegaram. É uma situação que se verifica frequentemente com certos carunchos ao encontrarem troncos de árvores mortas; verifica-se ainda com a abelha-mestra para assegurar a formação de enxames, e ainda por certos gafanhotos na identificação de locais de postura e por joaninhas para o respectivo repouso hibernal.

As feromonas de percurso ou rasto têm o efeito de indicar o mesmo percurso, para a localização duma fonte de alimentos, aos insectos da mesma colónia, como acontece, por exemplo, com as formigas. 
Na tabela 2 dão-se exemplos de feromonas de alarme, agregação e de percurso de certos tipos de insectos. As feromonas sexuais são, sem dúvida, as mais estudadas. São as mais importantes na vida de relação dos insectos e necessárias na aproximação dos sexos. O

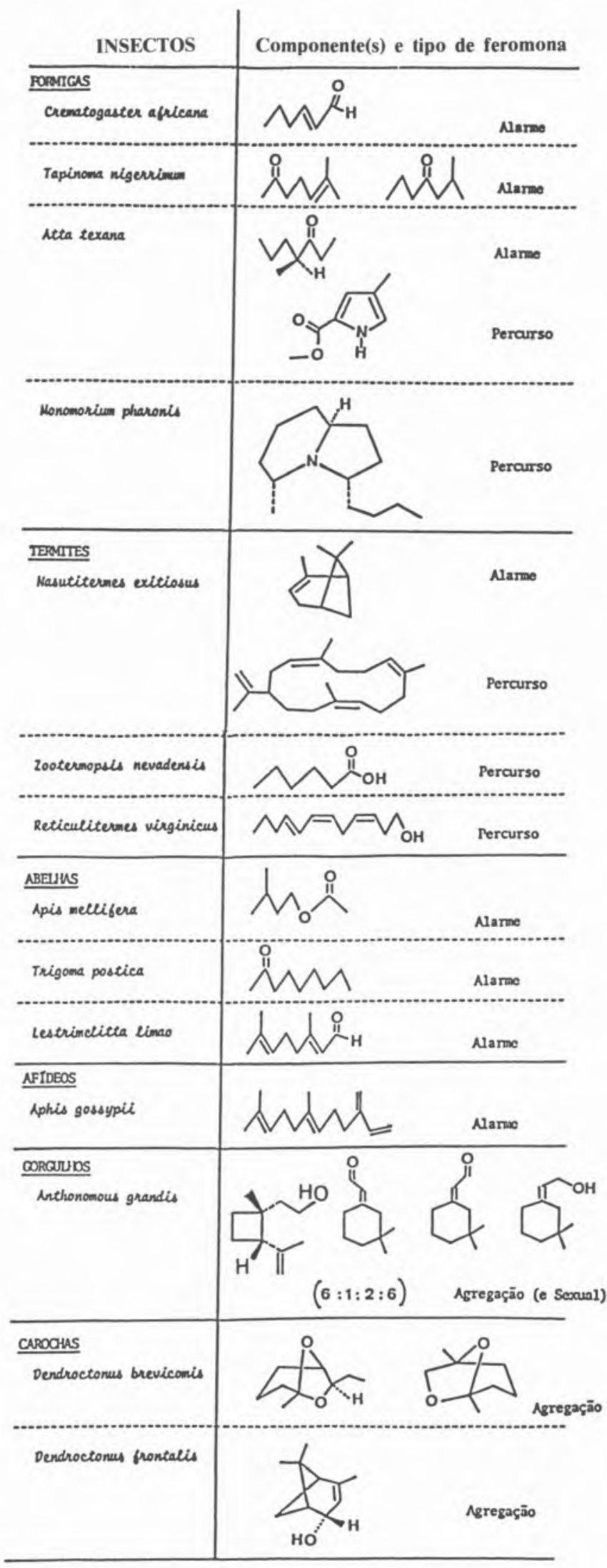

Tabela 2

Algumas feromonas de alarme, agregação e de percurso de diversos insectos acasalamento, e consequente propagação da espécie, depende, pois, de feromonas sexuais. As tentativas de controle de insectos têm sido feitas usando, principalmente, este tipo de feromonas.

$\mathrm{Na}$ tabela 3 são indicadas várias feromonas sexuais e respectivos tipos de insectos.

Como se pode concluir das tabelas 2 e 3 as feromonas podem ser constituídas por apenas um ou por vários compostos; neste caso cada composto é designado por componente da feromona. A proporção em que existem os vários componentes é muito importante pois, em geral, uma proporção diferente de alguns desses componentes é suficiente para ser detectada pelos insectos. É o caso das feromonas sexuais de algumas espécies afins de borboletas, apresentadas na tabela 4, as quais diferem entre si apenas nas proporções em que existem os seus componentes 6 .

Em muitas das espécies estudadas que usam feromonas com diversos componentes, alguns deles funcionam como sinergistas; assim o efeito total da feromona é maior que a soma dos efeitos de cada um dos componentes usado individualmente. Um exemplo elucidativo do fenómeno sinergético é o caso detectado por Klun 10 que verificou, em estudos com a traça Ostrinia nubilalis (cujas larvas são conhecidas por brocas de milho), serem os machos muito pouco atraídos pelo acetato de (Z)-11-tetradecenilo (6), enqanto que a traça Argyro-

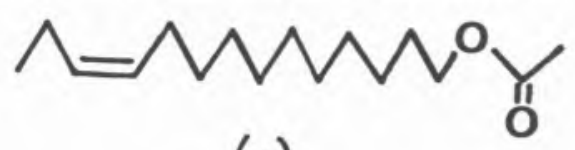

(6)

taenia velutinana (cujas larvas existem em macieiras, vinhas, árvores de folha caduca e coníferas) não sofria qualquer espécie de atracção motivada por esse composto. No entanto, depois de serem adicionadas pequenas quantidades do isómero $\mathrm{E}$ ao isómero $\mathrm{Z}$, ambas as espécies eram fortemente atraídas, apesar de nenhuma delas mostrar qualquer resposta ao isómero $\mathbf{E}$ puro.

Outro aspecto interessante é o facto de se verificar que a quiralidade é um factor preponderante na actividade feromonal. Nesses casos as feromonas são constituidas por uma ou mais formas enantioméricas. Os insectos utilizam somente um dos enantiómeros ou então uma mistura dos enantiómeros em proporções bem definidas, sendo de admitir que possuem um sistema receptor estereo-selectivo. A composição enantiomérica de feromonas é um facto de tal modo importante que mesmo pequenas quantidades de isómero "errado" podem inibir a resposta ao isómero "correcto". Para estes factos referir-se-ão apenas quatro casos dos muitos existentes na literatura.

A fenomona sexual da carocha fêmea, Popillia japonica, foi identificada como sendo a lactona (7), (R,Z)-5-(1-decenil)di-hidro-2(3H)-furanona 11 . $\mathrm{O}$ macho responde ao isómero $(\mathrm{R}, \mathrm{Z})$ puro, mas a sua resposta é fortemente inibida por pequenas quantidades do isómero $(\mathrm{S}, \mathrm{Z})(8)$.

(S)-(+)-4-metil-3-heptanona (9), é a principal feromona de alarme da formiga Atta texana. Verificou-se, neste caso, o que o (+)-enantiómero é cerca de 100 vezes mais activo que a forma levo-rotatória correspondente.

Verificou-se também no caso da carocha "Scolytus multistriatus", responsável pela propagação da "doença dos ulmeiros", que a sua feromona de agregação é 


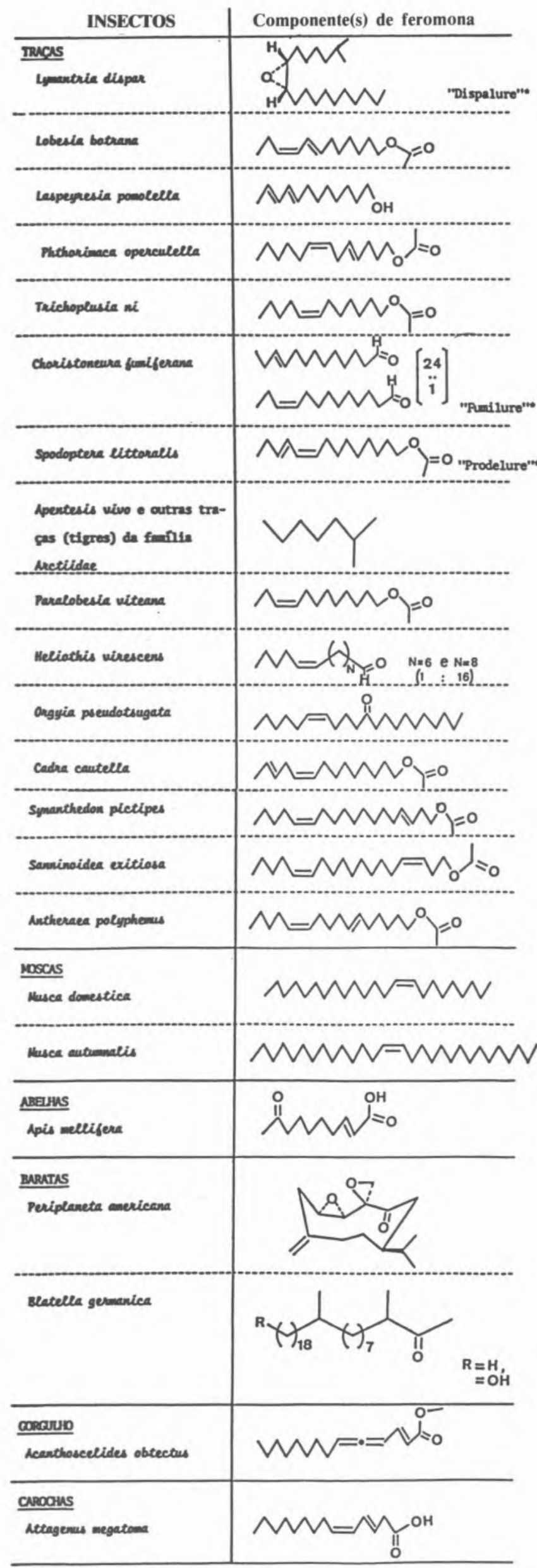

- Desigraçio conercial

Tabela 3

Algumas feromonas sexuais de Insectos

composta por três compostos actuando sinergisticamente 11,12: (-)-4-metil-3-heptanol (10), (-)-( $\alpha)$-multi-estriatina (11), e (-)- $\alpha$-cubebeno (12).

Uma praga que pode causar milhões de contos de prejuízos em arroz armazenado é o gorgulho Sitophilus oryzae. O componente principal da sua feromona de agregação acaba de ser identificado 13 como sendo (4R*,5S*)-4-metil-5-hidroxi-3-heptanona (13).

Isto significa que se se pretender fazer testes com compostos óptimamente activos será necessário usá-los numa forma enatiomericamente pura. Este facto constitui uma das principais dificuldades ao pretender-se fazer a sintese dessas feromonas. Descobrir rotas de síntese que levem ao estereo-isómero desejado, e o mais puro possível, com bom rendimento e com possibilidade de aplicação a nivel industrial, tem sido uma "arte" exposta em muitas e diversas publicações de Química Bio-Orgânica.

\section{CARACTERÍSTICAS DAS FEROMONAS}

Apesar do estudo dos compostos químicos envolvidos na comunicação entre os insectos ser, por si só, de grande interesse do ponto de vista puramente científico, é no entanto devido às perspectivas favoráveis do seu uso no controle desses artrópodes que se deve o trabalho intenso, especialmente nos últimos anos, de muitas equipas de investigadores.

Depois de tudo o que está dito será natural perguntar: "será realmente possível usar estes compostos para controlar os insectos?"'. Os testes até agora efectuados indicam que sim, embora haja ainda trabalho a efectuar para descobrir o melhor meio de os utilizar.

Se compararmos as características das feromonas com as dos insecticidas tradicionais será fácil de ver o porquê do interesse do seu estudo, comparação essa que é indicada a seguir 6 .

Feromonas

Insecticidas

- São necessárias quantidades diminutas $\left(10^{-18} \mathrm{~g}\right)$ para a mensagem.

- São altamente especificas, isto é, cada espécie tem o seu próprio "sinal quimico" e com uma relação de estrutura-actividade muito grande. Não destroem o equilibrio biológico.

- Não são venenosas e são biodegradáveis. Não poluem o Ambiente.

- A resistência é desconhecida e improvável.

- Espera-se que os custos sejam competitivos com os dos insecticidas, especialmente quando não for preciso usar mais de duas feromonas por cultura.
- São necessárias quantidades de cerca de $10^{12}$ vezes mais, isto é, cerca de $10^{-6} \mathrm{~g}$ /insecto para o matar.

- Não são selectivos. Podem matar não só os insectos prejudiciais mas também os bebéficos. Destroem o equilíbrio biológico.

- São venenosos para os animais, incluindo o Homem. Alguns deles, ou os seus produtos de degradação, são estáveis e acumulam-se, poluindo o Ambiente.

- Os insectos adquirem resistência contra os insecticidas, acabando estes por tornar-se quase inactivos e obrigando à introdução de novos compostos.

- $\mathrm{O}$ custo é muito alto. $\mathrm{O}$ uso anual, no mundo, de cerca de $2 \times 10^{6}$ toneladas é equivalente a um custo de $10^{9}$ contos. 


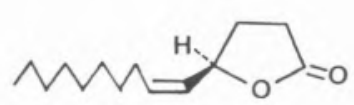

(7)

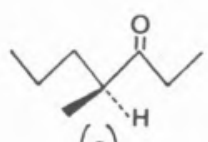

(9)

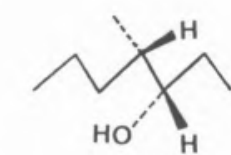

(10)

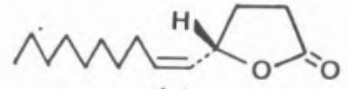

(8)

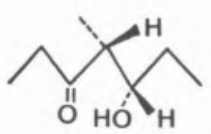

(13)

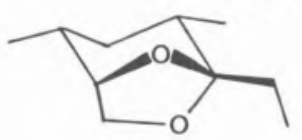

(11)

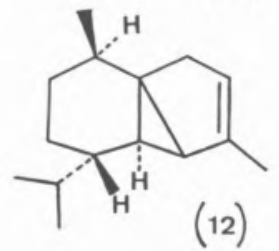

As conclusões desta comparação são óbvias. Mas como se poderão então aplicar estes compostos (feromonas), que não são pesticidas, no controle de pragas de insectos e especialmente na Agricultura?

\section{A APLICAÇÃO DAS FEROMONAS}

As feromonas sexuais de insectos são de importância vital para a sobreviência das respectivas espécies. Isto é especialmente importante nos casos de grande dispersão entre indivíduos de sexo oposto que raramente se encontrariam na ausência desses mensageiros químicos. As feromonas sexuais têm sido, assim, as de maior aplicação no controle de insectos.
A aplicação das feromonas no campo faz-se recorrendo ao uso de armadilhas 5,6. Existem vários modelos mas, dum modo geral, todas elas constam de um abrigo simples, o mais barato possivel e resistente às intempéries (os feitos de cartão plastificado têm dado bons resultados). No interior do abrigo é colocada uma cápsula contendo a feromona, havendo ainda uma superfície pegajosa para assegurar a captura. As cápsulas, de características muito variáveis, permitem a difusão controlada de feromona através duma rolha porosa. As distâncias de atracção poderão variar, consoante as espécies, desde alguns centímetros até alguns quilómetros. É realmente fantástica a sensibilidade das antenas receptoras.

Existem dois métodos gerais para a aplicação das feromonas no campo. $\mathrm{O}$ primeiro, em processo integrado com a "Luta Química", consiste em usá-las como monitoras para se decidir sobre o momento em que o nível económico de ataque se considera atingido. Este método utiliza armadilhas com quantidades muito pequenas da feromona, distribuídas pela cultura a proteger. Após contagem dos insectos capturados decide-se, relativamente ao pesticida, "quando, onde e quanto" se deve aplicar. Isto traduz-se pela redução drástica do número de aplicações e de quantidades do pesticida a usar. Em Portugal esta aplicação de feromonas para o aviso do bichado-da-macieira é já prática corrente e também, em menor escala, para as traças-da-uva 5 .

O segundo método de aplicação consiste em usar feromonas para reduzir drasticamente o número de acasalamentos, conseguindo-se, se tal acontecer, manter a população da praga em nível abaixo daquele considerado responsável por prejuízos económicos significativos.

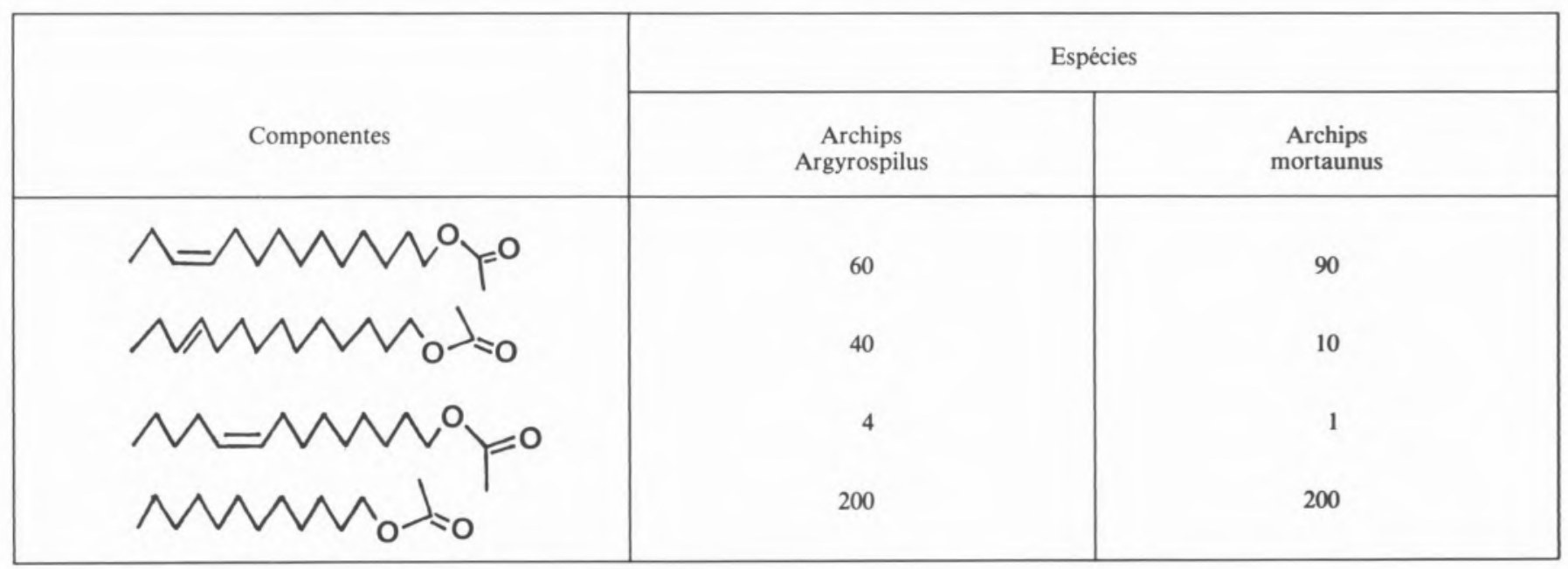

\begin{tabular}{|c|c|c|c|}
\hline \multirow{2}{*}{ Componentes } & & \multicolumn{2}{|c|}{ Espécies } \\
\cline { 2 - 4 } & $\begin{array}{c}\text { Pectinophora } \\
\text { gossypiella }\end{array}$ & $\begin{array}{c}\text { Pectinophora } \\
\text { endema }\end{array}$ & $\begin{array}{c}\text { Pectinophora } \\
\text { scutigera }\end{array}$ \\
\hline
\end{tabular}


Neste caso pouco ou nenhum pesticida será necessário aplicar. Esta situação poderá ser conseguida por uma das técnicas seguintes:

a) Captura maciça. Com esta técnica pretende-se capturar o maior número possível de reprodutores (principalmente machos, já que a maior parte das feromonas sexuais são emitidas por fêmeas), diminuindo então as possibilidades de acasalamento.

A captura maciça, só por si, é raramente suficiente. Há sempre a possibilidade de quase todos os machos terem fecundado algumas fêmeas antes de serem capturados. Por isso esta técnica é, geralmente, usada em combinação com a da confusão.

b) Confusão. Esta técnica consiste em distribuir um número elevado de armadilhas na área a proteger, provocando deste modo, uma "saturação" do ar com a feromona e assim os machos, ao receberem a mensagem de todas as direcções, não são mais capazes de localizar e fecundar as fêmeas.

O interesse em diminuir o número de acasalamentos é óbvio. Como os insectos têm um período de vida curto, a continuação das espécies deve-se à sua reprodução rápida e com grande número de larvas. Impedindo ou diminuindo acentuadamente o número de acasalamentos a população dos insectos baixará drasticamente em pouco tempo.

Uma situação análoga à que se observa por aplicação das técnicas referidas nas alíneas anteriores, e que lhes poderá servir de alternativa, é a resultante do uso de inibidores da actividade feromonal. A viabilidade deste processo dependerá da maior ou menor facilidade na obtenção desses compostos e dos seus graus de estabilidade.

Todas as possibilidades de controle de insectos já descritas têm sido objecto de estudos intensivos quer no laboratório, quer no campo. Dispõem-se já no mercado de muitas feronomas sexuais de insectos e muitas delas estão a ser usadas, com êxito, em diversos países 5. O que acontecerá, no futuro, relativamente ao uso desses compostos na Agricultura?

\section{PERSPECTIVAS FUTURAS NO USO DE FEROMONAS}

Convirá referir primeiramente que a utilização, com sucesso, das feromonas na Agricultura só será possível se houver uma colaboração activa entre químicos, biólogos, entomologistas, agrónomos e agricultores. Como consequência dessa interacção será necessário desenvolver um conjunto de acções visando atingir, nomeadamente, os seguintes objectivos 6:
- procurar isolar e caracterizar novas feromonas; - descobrir rotas simples e eficientes, com aplicação industrial, para a sintese destes compostos;

- encontrar novos tipos de armadilhas, tendo em consideração, para as diferentes pragas, os respectivos comportamentos, fisiologias, ciclos vitais, etc. Esses dispositivos deverão ainda proteger os compostos de oxidação e/ou degradação;

- estudar onde, quando, como e em que quantidade se devem usar as feromonas e ainda estudar a possibilidade de usar várias feromonas ao mesmo tempo (um "cocktail" de feromonas) para controlar um conjunto de pragas;

- estudar o efeito da aplicação repetida de feromonas no equilíbrio ecológico e a possibilidade de aparecimento de mutação (equivalente à resistência aos pesticidas).

Finalmente poder-se-á afirmar que, se houver uma boa colaboração entre todas as entidades a quem este tema interessa directamente (universidades, laboratórios de investigação estatais, indústrias químicas, etc.), o controle de pragas poderá ser feito muito mais facilmente e com menores riscos. Nesse caso será a próxima geração de "pesticidas" constituída por feromonas?

\section{REFERÊNCIAS}

1. Resultante do trabalho de A.C. Tomé na disciplina "Seminário" da Licenciatura em Química da Universidade de Aveiro.

2. J.S. Oakland, Chem. in Brit., 1981, 17, 430.

3. Guia dos Produtos Fitofarmacêuticos. Concentraçð̃es e Doses de Aplicação. Vol. 1. Direcção-Geral de Protecção da Produção Agricola; Oeiras, 1980.

4. E.A. Luna de Carvalho em "Guia Prático para a Identificação de Alguns Insectos de Armazéns e Produtos Armazenados"; pág. 307, Instituto de Investigação Científica Tropical, Lisboa, 1984.

5. Introdução à Protecção Integrada, Ed. P. Amaro e M. Baggiolini, vol. 1, Direcção-Geral de Protecção da Produção Agrícola, Lisboa, 1982.

6. A. Shani, J. Chem. Ed., 1982, 59, 579.

7. W.F. Wood, J. Chem. Ed., 1983, 60, 531.

8. A. Butenandt, R. Beckmann, D. Stamm, e E. Hecker, Z. Naturforsch, 1959, B14, 283.

9. C.G. Butler, R.K. Callow e N.C. Johnston, Nature, 1959, 184, 1871 .

10. J.A. Klun, O.L. Chapman, K.C. Mattes, P.W. Wojtkowski, M. Beroza e P.E. Sonnet, Science, 1973, 181, 661.

11. J.M. Brand, J.C. Young e R.M. Silverstein em "Progress in the Chemistry of Organic Natural Products”, vol. 37, pág. 97, Springer-Verlag, New York, 1979.

12. K. Beck, J. Chem. Ed., 1978, 55, 567.

13. N.R. Schmuff, J.K. Phillips, W.E. Burkholder, H.M. Fales, C. Chen, P.P. Roller e M. Ma, Tet. Letters, 1984, 25, 1533. 


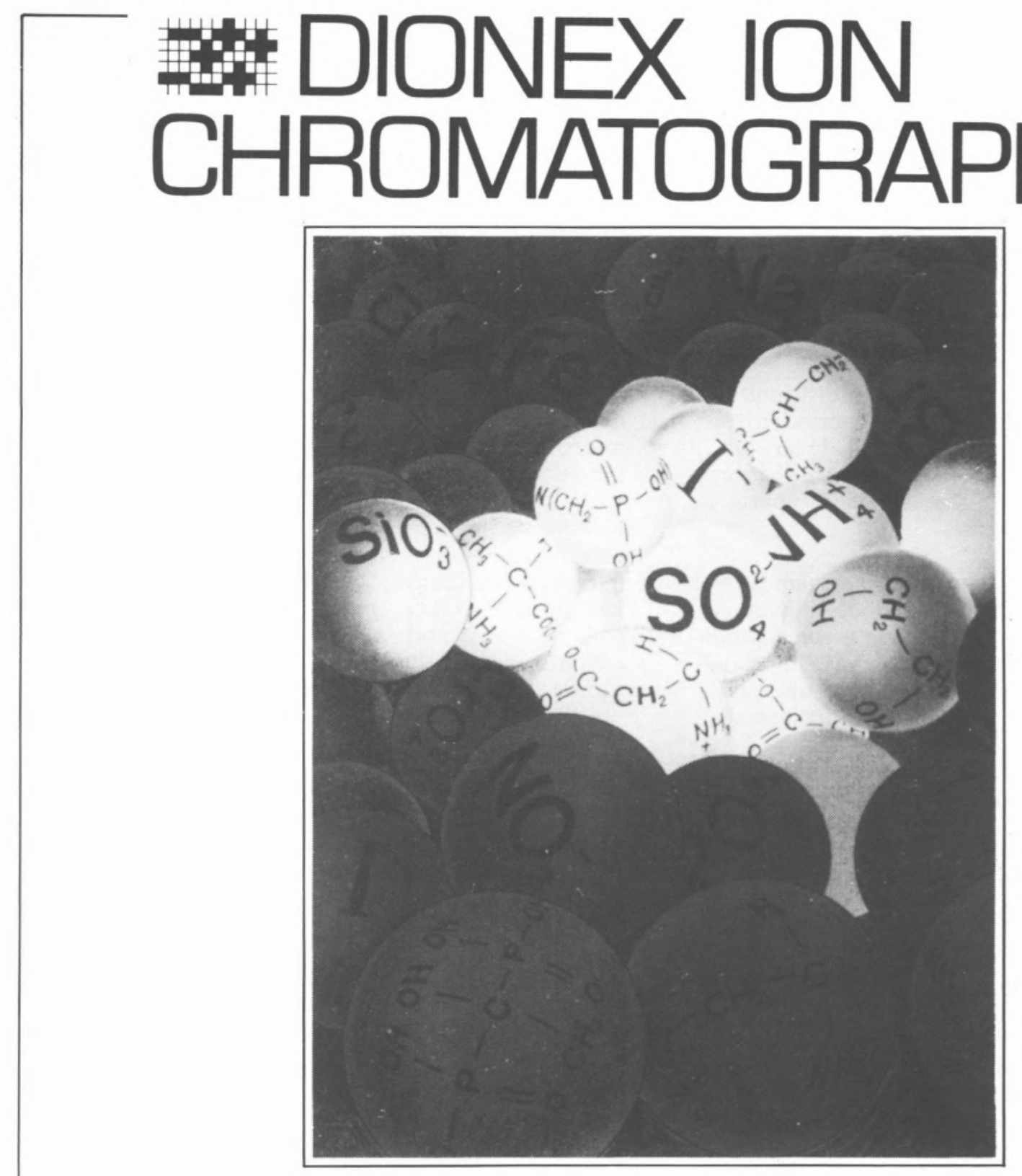

PARA ANÁLISES CROMATOGRÁFICAS ALTAMENTE EFICIENTES DE TODAS AS CLASSES DE COMPOSTOS POLARES E IÓNICOS

PEÇA A NOSSA

DOCUMENTAÇÃO
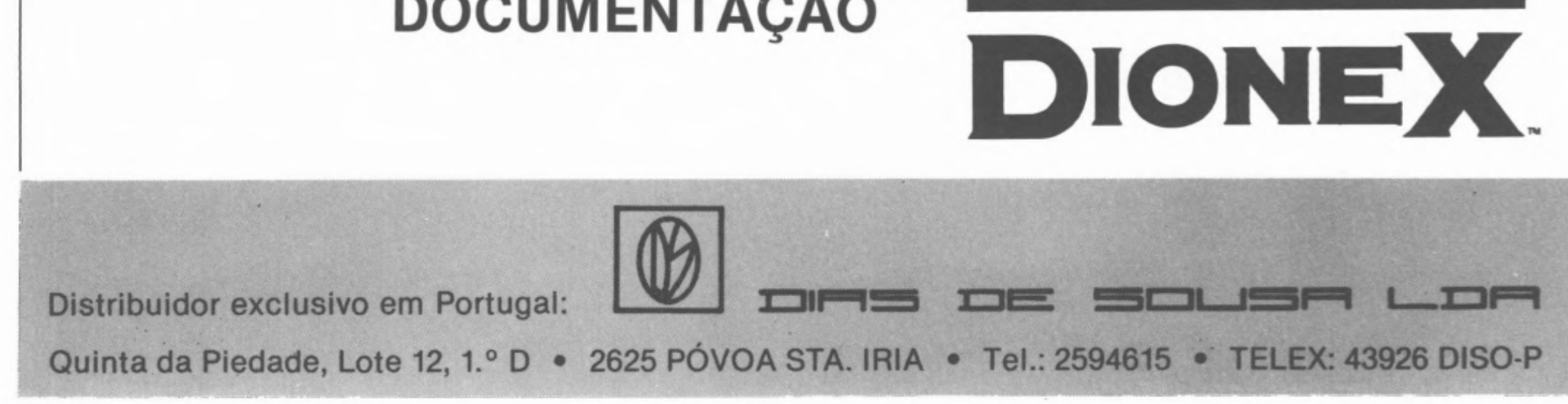